\title{
SISTEM INFORMASI MANAJEMEN KREDIT BERBASIS WEB PADA BANK PERKREDITAN RAKYAT GEMILANG TEMBILAHAN
}

\author{
Muhammad Budiman 1 , Usman 2 , Ilyas3 \\ Sistem Informasi, Fakultas Teknik dan Ilmu Komputer, Universitas Islam Indragiri, \\ Jl. Provinsi No. 01 Tembilahan Hulu, Indragiri Hilir, Riau-Indonesia \\ Email: budimanm440@gmail.com, usmanovsky13411@gmail.com, daengilyas01@gmail.com
}

\begin{abstract}
ABSTRAK
PD. BPR Gemilang Tembilahan adalah satu-satunya bank milik pemeritah daerah Indragiri Hilir yang salah satunya mempunyai produk pembiayaan dalam bentuk kredit dan saat ini sistem pengajuan kredit dan pengambilan keputusan di komite kredit masih belum terkomputerisasi karena masih menggunakan sistem manual yaitu penggunaan kertas dalam proses pengajuan kredit dan proses komite kredit berjalan sangat lama dikarenakan anggota komite kredit tidak semua berada ditempat dan Ketika terjadi kesalahan dalam pencatatan dalam sebuah kegiatan operasional bank akan terganggu, akibatnya ada pihak yang merasa dirugikan, terutama pada proses laporan. Sehingga menimbulkan data yang tidak akurat, dan tidak relevan sehingga proses pelayanan pun akan menjadi terhambat.Dengan demikian, adanya kebutuhan sistem informasi yang semakin lama semakin meningkat, maka diperlukan sistem yang baik agar memudahkan semua proses.Dalam penelitian ini penulis menggunakan metode analisis PIECES, untuk menganalisa sistem yang dibutuhkan maka penulis berusaha mengumpulkan data dengan cara observasi dan wawancara langsung kelapangan menjumpai nasabah dan pimpinan bank BPR Gemilang tembilahan. Rancangan sistem ini menggunakan bahasa pemrograman PHP dan XAMPP dalam mengolah atau membuat database, dreamweaver untuk desain dan UML (Unified Modelling Language) untuk model sistem. Hasil penelitian ini berupa Sistem Informasi Pengajuan Kredit yang berbasis web. Dengan adanya sistem ini dapat mempercepat proses pengajuan kredit serta menjadi lebih akurat dalam informasi yang diperoleh.

Keywords: Sistem, informasi, kredit, BPR, Gemilang
\end{abstract}

\section{PENDAHULUAN}

Pada perkembangan dunia teknologi saat ini sudah mulai berkembang semakin pesat dan banyak dimanfaatkan pada perusahaan yang bergerak di bidang produksi, bidang jasa, bidang pembiayaan dan bidang usaha lainnya. Sehingga penanganan akan kebutuhan informasi yang tepat dan akurat dapat terpenuhi. Dengan adanya komputer yang mendukung sebagai alat pengolahan data, maka pekerjaan manusia akan lebih ringan karena dapat dilakukan dengan komputer dalam waktu yang relatif singkat dan juga menghemat biaya dan tenaga.

Kebutuhan masyarakat akan pembiayaan sekarang ini semakin tinggi, seiring dengan perkembangan teknologi berkembang pula kebutuhan hidup yang meningkat mengikuti arus perkembangan zaman, sehingga mengakibatkan semakin banyak pula lembaga pembiayaan baik itu bank maupun lembaga pembiayaan bukan bank yang mana lembaga pembiayaan tersebut menjadi tujuan dari masyarakat untuk memenuhi kebutuhan khususnya pembiayaan, baik itu pembiyaan dalam bentuk penyediaan dana maupun barang .

Perbankan dalam kehidupan modern saat ini sudah menjadi suatu kebutuhan yang cukup penting bagi masyarakat. Banyak masyarakat yang ingin membangun usaha dan pembelian suatu barang tetapi terhambat oleh biaya dikarenakan harus membayar secara tunai. Oleh karana itu PD. Bank Perkreditan Rakyat Gemilang Tembilahan menawarkan program pembiayaan dengan bunga yang rendah dan mudah .

Pengajuan kredit calon nasabah yang berjalan di Bank Perkreditan Rakyat Gemilang Tembilahan saat ini dirasa masih belum optimal karena sistem yang digunakan secara manual serta membutuhkan waktu yang lama dan proses analisa di komite kredit masih belum maksimal dikarnakan keberadaan tiap Budi, Sistem Informasi Manajemen Kredit Berbasis Web PadaBankPerkreditan Rakyat Gemilang Tembilahan 
anggota komite kredit jarang ditempat. Dari hal tersebut ditemui beberapa kendala dalam proses pengajuan kredit yang diajukan oleh calon nasabah. Untuk itu, diperlukan suatu sistem informasi yang dapat menangani masalah tersebut

\section{TINJAUAN PUSTAKA}

Pada tahun 2015 dilakukan penelitian PERANCANGAN SISTEM INFORMASI PENGAJUAN KREDIT BERBASIS WEB PADA PT. BPR Kredit Mandiri Indonesia Cabang Bekasi oleh Ganda Wijaya dan Melza Sari STEMIK Nusa Mandiri Jakarta. Berdasarkan hasil penelitian yang sudah berlangsung maka berdasarkan analisa yang dilakukan, sistem pengajuan kredit yang sedang berjalan saat ini pada PT.BPR Kredit Mandiri Indonesia sudah berjalan dengan baik, namun masih mengunakan sistem manual pada proses pengajuan kreditnya yang mengharuskan nasabahnya datang langsung ke bank. hal itu tentu tidak efektif dan efisien. Pengimputan pengajuan kredit oleh Account Officer yang memasukan data nasabah kembali membutuhkan waktu yang cukup lama dan juga rentan akan kesalahan dalam proses penginputan data.

Untuk itu melalui penelitian ini dibangunlah sistem informasi pengajuan kredit berbasis web untuk mengatasi kendala yang ada. Sistem informasi dibuat dengan mempelajari sistem yang sedang berjalan serta membuat analisa kebutuhan. Selain itu sistem pengajuan kredit berbasis web juga dapat menghasilkan laporan yang dapat sebagai bahan pertimbangan dalam mengambil keputusan terkait dalam pengajuan kredit.

Tahun 2017 pada jurnal Indra Griha Tofik Isa dan George Pri Hartawan Universitas Muhammadiyah Sukabumi melakukan penelitian dengan judul PERANCANGAN APLIKASI KOPERASI SIMPAN PINJAM BERBASIS WEB (STUDI KASUS KOPERASI MITRA SETIA). Pada penelitian ini bahwa perangkat lunak yang dilakukan pada penelitian ini akan menggunakan metode berorientasi objek, adapun tahapannya Analisis sistem dilakukan dengan metode Object Oriented Analysis (OOA) atau analisis berorientasi objek. Sistem ini akan dirancang dengan menggunakan metode Object Oriented Design (OOD) atau perancangan berorientasi objek dengan menggambarkan rancangan sistem menggunakan diagram UML (Unified Modelling Language) yang terdiri dari Use Case Diagram, Aktivity Diagram, Squence Diagram dan Class Diagram Masing-masing aktor akan tergambarkan dengan jelas pada diagram di atas memiliki tugas dan fungsi yang berbeda.

Pada tahun 2018 dilakukan penelitian PERANCANGAN SISTEM INFORMASI RENTAL MOBIL BERBASIS WEB PADA PT. APM RENT CAR oleh Yunahar Heriyanto Manajemen informatika, AMIK Mahaputra Riau Jl. HR. Soebrantas No. 77 Panam. Dengan telah terselesaikannya seluruh kegiatan penelitian, analisis sistem, perancangan program sampai dengan implementasi dan pembahasan, maka peneliti dapat disimpulan bahwa Dalam membangun web pada penelitian ini terdapat dua web dengan fungsi berbeda namun saling terkoneksi yaitu web untuk pelanggan dan web untuk admin. Web untuk pelanggan digunakan untuk mendapatkan informasi serta melakukan proses rental mobil dan web admin digunakan untuk mengelola data pada web rental mobil PT.APM, dan di Dalam web ini terdapat beberapa laporan sehingga mempermudah dalam mengelola data, yaitu laporan semua mobil, semua pelanggan, laporan konfirmasi dan laporan semua transaksi. Laporan transaksi bisa diakses berdasarkan periode tanggal, bulan, dan tahun, admin dapat mengelola mobil, dan harga rental sehingga data dapat berubah sewaktu-waktu dan promosi rental mobil PT.APM dapat lebih optimal.

Berdasar penelitian terdahulu tahun 2018 dengan judul penelitian SISTEM INFORMASI PENGAJUAN KREDIT BERBASIS WEB PADA KOPERASI INTAN ABADI BANYUWANGI. Oleh Putri Nadia Ayu Rahmawati dan Ahmad Chusyairi STIKOM PGRI Banyuwangi Jl. Jend. A. Yani No.80 Banyuwangi Jawa Timur 68416 INDONESIA. Dengan penelitian ini dapat disimpulkan bahwa sistem ini hantya terdiri dari tiga aktor yaitu nasabah, surveyor dan manajer dan metode pengembangan sistem mengunakan Waterfal. Fitur-fitur yang terdapat dalam Sistem Informasi Pengajuan Kredit Berbasis Web Pada Koperasi Intan Abadi Banyuwangi diantaranya :Information Page, Member Area, Admin Pinjaman, Survey, manager dan Data Pinjaman.

Budi, Sistem Informasi Manajemen KreditBerbasis Web PadaBankPerkreditan Rakyat Gemilang Tembilahan 
Pada tahun 2018 Muhtajuddin Danny Program Studi Teknik Informatika Sekolah Tinggi Teknologi Pelita Bangsa melakukan penelitian dengan judul SISTEM INFORMASI PINJAMAN DANA TUNAI BERBASIS WEB PHP DENGAN MENGGUNAKAN DATABASE MYSQL. Hasil penelitiannya adalah didalam pengembangan sistem tersebut terdapat form menu penjamin dalam artian disini terdapat seseorang yang menjamin pinjaman, dan dalam proses survey masih mengunakan map untuk membawa data untuk mengunjungi calon nasabah kemudian permohonan dan persaratan berbentuk fisik harus dipersiapkan pada waktu kunjungan survey, selain itu perancangan mengunakan $U M L$ yang terdiri dari Use Case Diagram, Aktivity Diagram, Squence Diagram, Class Diagram.

Pada penelitian terdahulu pada tahun 2016 dengan judul PERANCANGAN SISTEM INFORMASI KREDIT MIKRO MAHASISWA BERBASIS WEB oleh Lasminiasih dan kawan-kawan Universitas Gunadarma. Dalam penelitian ini, peneliti mengunakan metode deskriptif yaitu dengan mengumpulkan data dan informasi di Pusat Bisnis dan Kewirausahaan Universitas Gunadarma. Dalam pengambilan data peneliti melakukan dengan cara observasi secara langsung terhadap bagian administrasi dan keuangan dan dilakukan dengan cara wawancara secara langsung dengan bagian keuangan dan administrasi Pusat Bisnis dan Kewirausahaan Universitas Gunadarma. Alat analisis yang digunakan adalah Flowchart (bagan alir) merupakan representasi secara grafik dari satu algoritma atau prosedur untuk menyelesaikan suatu masalah. DFD (Data Flow Diagram) adalah suatu diagram yang menggunakan notasi untuk menggambarkan arus data sistem, yang penggunanya sangat membantu untuk memahami secara logika, terstruktur dan jelas. Implementasi program menggunakan bahasa PHP (hypertext preprocessor) yang merupakan program yang dikembangkan secara bersama oleh para programmer. PHP dikembangkan khususnya untuk mengakses dan memanipulasi data yang ada di database server opensource seperti MySQL.

Pada penelitian terdahulu pada tahun 2019 oleh Muhammad Samsudin dan kawan - kawan Politeknik Sain dan Teknologi Wiratama Maluku Utara dengan judul SISTEM INFORMASI PENGKREDITAN NASABAH PADA KOPRASI SIMPAN PINJAM SEJAHTERA BARU KOTA TERNATE BERBASIS WEB, Dalam penelitian ini Penerapan Sistem informasi Perkreditan Koperasi Berbasis web sangat membantu masyarakat dalam mengajukan pinjaman, dimana masyarakat cukup mendaftar dngan cara mengakses website Koperasi Sejahtera Baru. Proses pengolahan data menjadi lebih mudah, karena data terkoneksi ke dalam database sehingga memudahkan dalam proses pencarian, penambahan data dan perbaikan data. Selain itu System keamanan menjadi lebih baik, karena aplikasi dibuatkan system Login, dimana pengguna yang akan melakukan akses dibedakan menjadi dua, yaitu admin dan tamu, admin bisa melihat dan menginput semua data yang ada didalam aplikasi sedangkan Tamu/pengunjung hanya bisa mengakses halaman depannya saja dan dalam hal jadwal pemeliharaan terhadap system secara berkala baik itu menyangkut data atau informasi, akan dikembangkan kembali. Selain itu sistem aplikasi ini belum bisa memutuskan pinjaman nasabah dapat diterima atau ditolak.

\section{METODE PENELITIAN}

\subsection{Alur Penelitian}

Alur penelitian merupakan urutan langkah-langkah kerja dalam melakukan penelitian agar penulisan lebih terarah dalam penyelesaian masalah yang dibahas. Adapun tahapan alur penelitian dapat dilihat pada gambar di bawah ini : 


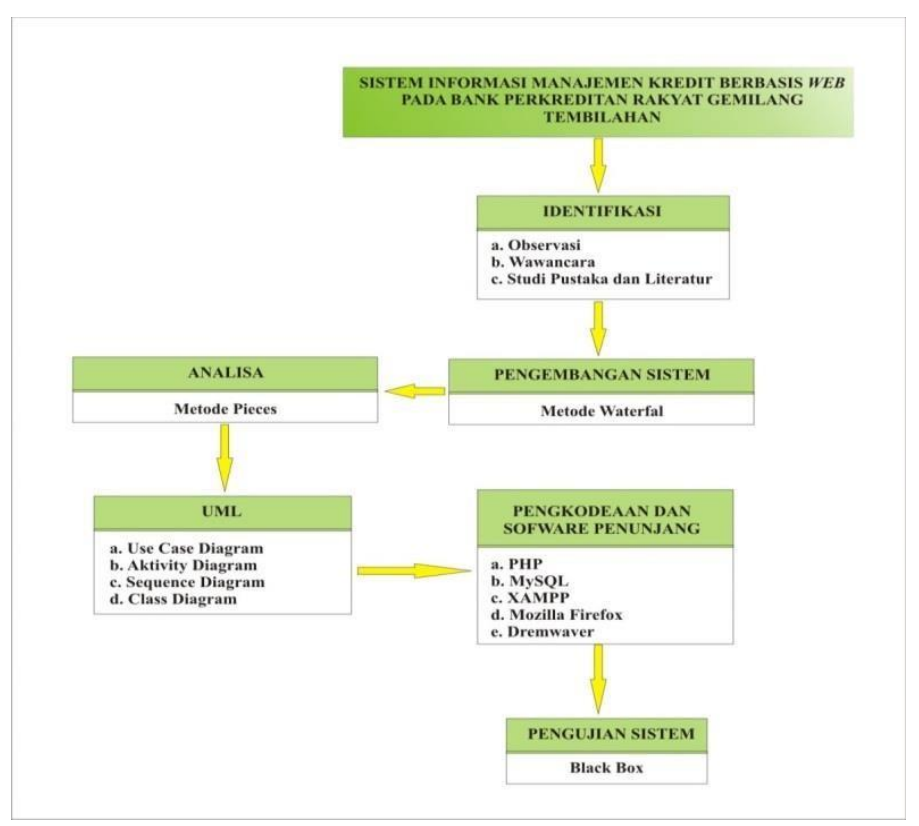
berikut:

Penjelasan tentang gambar 3.1 tahapan alur penelitian yang penulis lakukan adalah sebagai

\section{Identifikasi Masalah}

Pada tahap identifikasi masalah diharapkan penulis dapat mengerti masalah yang diteliti. Tahap awal identifikasi masalah adalah merumuskan masalah agar penelitian ini dapat berjalan terarah dan teratur sesuai dengan masalah yang diteliti.

\section{Studi Literatur}

Pada tahap ini penulis mempelajari penelitian tedahulu agar dapat mendukung pengembangan sistem yang berasal dari materi-materi yang sudah ada baik berupa buku, jurnal, website dan lain sebagainya yang ada hubungannya dengan penelitian ini. Dengan mempelajari atau mengulas jurnal tersebut, maka penulis akan lebih memahami bagaimana mengembangkan sistem dengan lebih baik.

3. Pengumpulan Data

Pengumpulan data dalam penelitian ini bertujuan untuk mendukung proses penelitian. Beberapa teknik yang digunakan adalah sebagai berikut :

a. Observasi (Observation)

Observasi adalah penelitian yang dilakukan dengan cara mengadakan pengamatan langsung terhadap calon nasabah dan nasabah serta langsung mengamati proses komite kredit di bank perkreditan rakyat gemilang .

b. Wawancara (Interview)

Pada teknik wawancara ini penulis bertanya secara langsung kepada calon nasabah dan nasabah serta komite kredit dan pimpinan bank perkreditan rakyat gemilang Tembilahan guna untuk mengetahui proses dan hal-hal lain yang penulis butuhkan yang berkaitan dengan penelitian ini.

\section{Analisis Data}

Metode PIECES adalah metode analisis sebagai dasar untuk memperoleh pokok-pokok permasalahan yang lebih spesifik. Dalam menganalisis sebuah sistem, biasanya akan dilakukan terhadap beberapa aspek antara lain adalah kinerja, informasi, ekonomi, keamanan aplikasi, efisiensi dan pelayanan pelanggan. Analisis ini disebut dengan PIECES Analysis (Performance, Information, Economy, Control, Eficiency and Service) Kinerja (Performance)

pada sistem yang berjalan Pada sistem berjalan saat ini, permasalahan yang dihadapi saat ini mulai dari pengajuan permohonan kredit hingga respon komite kredit masih dilakukan secara manual sehingga waktu yang diperlukan relative lama hal ini dikarenakan sistem masih ofline.

Budi, Sistem Informasi Manajemen Kredit Berbasis Web PadaBankPerkreditan Rakyat Gemilang Tembilahan 
5. Perancangan Sistem

Membuat rancangagan sistem informasi manajemen kredit pada bank perkreditan gemilang Tembilahan dengan menggunakan pemodelan

UML (Unified Modeling Language) dengan langkah -langkah sebagai berikut :

a. Menentukan perencanaan awal Pada tahap ini dibuat perencanaan mengenai kegiatan apa saja yang akan dilakukan beserta

b. Melakukan analisis proses pengajuan dan proses komite kredit pada bank perkreditan rakyat gemilang Tembilahan.

c. Memodelkan sistem informasi dengan menggunakan UML

Pada tahap ini dibuat pemodelan kebutuhan sistem informasi dengan menggunakan diagram UML yaitu Use Case Diagram, Activity Diagram, Squence Diagram, Class Diagram.

d. Membangun prototype sistem informasi

Pada tahap ini dibuat prototype sistem berupa user interface dengan menggunakan bahasa pemograman web.

\subsection{Bahan Penelitian}

Bahan penelitian yang dibutuhkan dalam perancangan sistem informasi manajemen kredit pada bank perkreditan rakyat gemilang Tembilahan yaitu :
a. Contoh formulir permohonan kredit.
b. Contoh form surveyor
c. Contoh form analisa dan komite kredit

\subsection{Alat Penelitian}

Merupakan perangkat yang digunakan penulis dalam pengembangan sistem. Adapun perangkat yang penulis gunakan dalam pengembangan sistem adalah sebagai berikut :

1. Perangkat Lunak (software)

\begin{tabular}{|l|l|l|}
\hline No & Nama Perangkat Lunak & Minimal Spesifikasi \\
\hline 1 & Sistem Operasi & Microsoft Windows 7 64 bit \\
\hline 2 & Pengolahan Kata & Microsoft Office Word 2010 \\
\hline 3 & Pengolahan Video & Ulead Studiol1 \\
\hline
\end{tabular}

2. Perangkat Keras (Hardware)

\begin{tabular}{|l|l|l|}
\hline No & Nama Perangkat Keras & Minimal Spesifikasi \\
\hline 1 & PC & Intel(R) core $\mathrm{TM}$ i3-4150 cpu @ 3.50 Hz \\
\hline 2 & Memori & $4.00 \mathrm{~GB}$ \\
\hline 3 & Hardisk & $1 \mathrm{~TB}$ \\
\hline 4 & Monitor & LCD 15 Inch \\
\hline 5 & Hand pone & Oppo F7 4XARM Cortex-A73@ $1,99 \mathrm{GHz}$ \\
\hline
\end{tabular}

\section{HASIL DAN PEMBAHASAN}

(Tulis di sini) ... Bagian ini menyajikan hasil penelitian. Hasil penelitian dapat dilengkapi dengan tabel, grafik (gambar), dan/atau bagan. Bagian pembahasan memaparkan hasil pengolahan data, menginterpretasikan penemuan secara logis, mengaitkan dengan sumber rujukan yang relevan. [Times New Roman, 11, normal], spasi 1. Format gambar png/jpg. 


\section{KESIMPULAN}

Setelah melakukan rancang bangun Sistem Informasi Manajemen Kredit berbasis Web pada Bank Perkreditan Rakyat Gemilang Tembilahan dapat diambil kesimpulan sebagai berikut:

1. Dengan adanya sistem informasi manajemen kredit pada Bank Perkreditan Rakyat Gemilang Tembilahan, calon nasabah kredit dapat melakukan pengajuan secara terkomputerisasi yang berbasis web.

2. Sistem penyimpanan berkas dilakukan secara terkomputerisasi sehingga mengurangi pengunaan kertas dan mengantisipasi kehilangan dan kerusakan berkas, selain itu dapat memudahkan karyawan bagian kredit mencari berkas nasabah.

3. Pada sistem ini Proses pengajuan kredit dapat dilakukan lebih cepat dan akurat.

4. Dengan adanya sistem ini dapat memudahkan bagian komite kredit untuk melakukan analisa permohonan kredit.

5. Sistem ini dapat memudahkan calon nasabah untuk melihat status pengajuan kredit.

\section{REFERENSI}

[1] Akbar, L. S. (2019). Implementasi Sistem Informasi Layanan Pariwisata . Jurnal Penelitian Teknik Informatika, 13-23.

[2] Akbar, R. (2019). Perancangan Aplikasi Pembayaran Non Tunai untuk Pengelolaan Bisnis. jurnal.umj.ac.id/index.php/semnastek, 1-13.

[3] Danny, M. (2018). SISTEM INFORMASI PINJAMAN DANA TUNAI BERBASIS WEB PHP. Jurnal TEKNOM, 1-8.

[4] Driyani, D. (2018). PERANCANGAN MEDIA PEMBELAJARAN SEKOLAH DASAR. Jurnal String, 35-43.

[5] Ganda wijaya, D. (2015). Perancangan Sistem Informasi Pengajuan Kredit Berbasis Web. IJSEIndonesian Journal on Software Engineering , 98-104.

[6] Heriyanto, Y. (2018). PERANCANGAN SISTEM INFORMASI RENTAL MOBIL BERBASIS WEB. Jurnal Intra-Tech, 64-77.

[7] Indra Griha Tofik Isa, D. (2017). PERANCANGAN APLIKASI KOPERASI SIMPAN PINJAM BERBASIS WEB. Universttas Muhammadiyah Sukabumi , 139-151.

[8] Lasminiasih, D. (2016). PERANCANGAN SISTEM INFORMASI KREDIT MIKRO MAHASISWA. Jurnal Sistem Informasi (JSI), 883-893.

[9] Muhammad Samsudin, D. (2019). Sistem Informasi Pengkreditan Nasabah Pada Koperasi Simpan Pinjam. Jurnal Ilmiah ILKOMINFO - Jurnal Ilmu Komputer dan Informatika,11-23.

[10] Naomi, M. (2019). Analisa Dan Perancangan Sistem Pengaduan Mahasiswa Berbasis. JURNAL SISTEM INFORMASI DAN E-BISNIS, 185-193.

[11] Putra, D. W. (2019). Unified Modelling Language . Jurnal TEKNOIF, 32-39.

[12] Putri Nadia Ayu Rahmawati, D. (2018). SISTEM INFORMASI PENGAJUAN KREDIT

BERBASIS WEB. Jurnal Teknologi Informasi , 73-77.

[13] Santoso, S. (2018). Aplikasi Sistem Informasi Pengajuan Kredit Berbasis Web. Konferensi Nasional Sistem Informasi, 849-855.

[14] Setiyani, L. (2019). PENGUJIAN SISTEM INFORMASI INVENTORY PADA PERUSAHAAN. Jurnal Ilmu Komputer dan Teknologi Informasi, 20-27.

[15] Sonata, F. (2019). Pemanfaatan UML (Unified Modeling Language) Dalam Perancangan. Jurnal Komunika, 22-31.

[16] Suandi, A. (2017). Pengujian Sistem Informasi E-commerce Usaha. INFORMATION SYSTEM FOR EDUCATORS AND PROFESSIONALS, 61-70.

Budi, Sistem Informasi Manajemen Kredit Berbasis Web PadaBank Perkreditan Rakyat Gemilang Tembilahan 
[17] Sukmawat, R. (2019). iUML, Perancangan Proses Bisnis Menggunakan. Jurnal Ilmiah Penelitian dan Penerapan Teknologi Sistem Informasi, 104-115. 